\title{
KNOWLEDGE ATTITUDE AND PRACTICE TOWARD COVID-19 DISEASE AMONG VARIOUS PROFESSIONALS: A CROSS-SECTIONAL ONLINE SURVEY
}

\author{
ABEETHA $S^{1}$, RAMYA $K^{1}$, BHAGYASHREE ${ }^{1}$, SUMA $S^{1}$, SUREKA $\mathbf{V}^{1}$, ASHUTOSH KOTHARI ${ }^{2}$ \\ ${ }^{1}$ Department of Physiology, A.C.S. Medical College and Hospital, Chennai, Tamil Nadu, India. ${ }^{2}$ National Fellow, National Health Systems \\ Resource Centre, Ministry of Health and Family Welfare, Government of India, New Delhi, India. Email: msrenu01@gmail.com
}

Received: 31 December 2020, Revised and Accepted: 13 February 2021

\section{ABSTRACT}

Objectives: This study aims to assess the knowledge, attitude, and practice associated with COVID-19 disease by undertaking a web-based online survey.

Methods: A cross-sectional survey was conducted all over India during the initial phase of COVID-19 hit between March 19, 2020, and March 29, 2020. Anyone aged 18 years and above using social media were included in the study. The questionnaire had a section on sociodemography which had questions regarding age, gender, marital status, and occupation. This was followed by questions on knowledge, attitude, and practice regarding the COVID-19 pandemic. The knowledge scores were summarized as median with interquartile range as the data followed a non-normal distribution. Attitude and practice questions were summarized individually as proportions and its association with socio-demographic variables was established using Chi-square test. The statistical significance was set at $\mathrm{p}<0.05$.

Results: Occupational groups, marital status, and age group had significant difference between the groups with at least one of the practices with $\mathrm{p}<0.05$.

Conclusion: Since the study provides enhancing effect of knowledge toward protective behaviors, the awareness raising activities and health education through mass media and campaigns, this should urgently be conducted focusing on effectiveness of hand washing, cough etiquette, social distancing, and responsibility to inform suspected cases to local health authority to prevent COVID-19.

Keywords: COVID-19, Knowledge, Attitude, Practice.

(C) 2021 The Authors. Published by Innovare Academic Sciences Pvt Ltd. This is an open access article under the CC BY license (http://creativecommons.org/ licenses/by/4.0/) DOI: http://dx.doi.org/10.22159/ajpcr.2021v14i4.40671. Journal homepage: https://innovareacademics.in/journals/index.php/ajpcr

\section{INTRODUCTION}

COVID-19 was declared a pandemic by the WHO on March 11, 2020. Earlier the focus of spread was centered on China; it has now shifted to Europe and North America. The WHO has advised countries to take a holistic approach engaging the whole-of-society to combat with the disease. It was suggested that infections can be prevented only if the mass awareness is created among the population which would eventually save lives and minimize impact of such disease.

In India, clusters and large outbreaks have been noted in parts of the country and unless they are contained in right time; the risk of further spread remains very high. The mode of transmission is either direct (droplets nuclei) or indirect contact (contaminated surface). As on April 2020, recovery rate of patients is at $12.02 \%$ which far exceeds fatality rate of $3.3 \%$. Taking a glance at this data, there are still chances of outbreak in India due to challenges such as practicing social distancing, accessibility, implementing personal hygiene especially in areas where population density is high. To prevent the community spread of disease in India, Ministry of Health and Family Welfare, Government of India has suggested to follow physical/social distancing as an important public health intervention. The government of India has adopted some unprecedented measure to control the transmission viz- $a$-viz closing of all public places, discontinuing all gathering either of religious or whatsoever, suspension of all public transport, inter and intra districts zero movement unless an extraordinary situation. The government also parallelly focused on increased testing of suspected cases and their contacts, readiness in terms of well-equipped Intensive Care Unit facilities, dedicated COVID Care Centre and follow-up of cases if home quarantined. The next step of establishing a special surveillance system exclusively for emerging trend of pre-symptomatic/asymptomatic and symptomatic cases at community level is under process. This will aid in increased and improved vigilance to identify all COVID cases.

The knowledge and attitude among general public during such pandemic situation could determine people adherence to such containment measures and further risk reduction [1,2]. To ensure "flattening of the curve" in India, as the disease is evolving, an extensive and effective mitigation and containment efforts will be required and for that perhaps health authorities will need timely and accurate data to design policies and interventions.

During the emergence of COVID-19, hitherto, public health responses such as their awareness on wearing masks, general symptoms, physical distancing, and travel plans have not been explored. This study aims to assess the knowledge, attitude, and practice associated with COVID-19 disease by undertaking a web-based online survey. The objective of this study was to assess the knowledge, attitude, and practice toward COVID-19, an emerging pandemic among various professionals.

\section{METHODOLOGY}

A cross-sectional survey was conducted all over India during the initial phase of COVID-19 hit between March 19, 2020, and March 29, 2020. Anyone aged 18 years and above was considered eligible for participation in the study. Online platforms such as WhatsApp and Facebook were used for data collection. Google forms were the tool of choice because of its ease in building the questionnaire, circulating, and handling of the data. The form had a brief introduction regarding the purpose of the study so as to obtain the consent from the participant. Participants were also assured about confidentiality of the data provided by them. The questionnaire was circulated in various groups as links by the investigator and his network. 
The questionnaire had a section on sociodemography which had questions regarding age, gender, marital status, and occupation. This was followed by questions on knowledge, attitude, and practice regarding the COVID-19 pandemic. The questionnaire used for this study was adopted from a study in china. The section on knowledge regarding COVID-19 consisted of 12 questions which were developed on the basis of clinical presentation of the disease, its transmission route, and methods of prevention and control. Attitude and practices section consisted of two questions each. Questions on knowledge had true, false, and do not know as options while attitude and practice had options yes/no. Each correct answer in the knowledge section was scored 1 and if the answer was incorrect or unknown, it was scored 0 . Therefore, the score ranged between 0 and 12 . Higher the score represents better knowledge.

The data collected were exported as Comma Separated value (CSV) files and imported to Stata version 14 for analysis. All the socio-demographic variable was summarized as proportions with $95 \%$ confidence interval. The knowledge scores were summarized as median with interquartile range as the data followed a non-normal distribution. Its association with sociodemography was assessed using non-parametric tests such as Mann-Whitney U-test or Kruskal-Wallis test as appropriate. Attitude and practice questions were summarized individually as proportions and its association with socio-demographic variables was established using chi-square test. The statistical significance was set at $\mathrm{p}<0.05$

\section{RESULTS}

A total of 449 participants completed the survey. About $57 \%$ of the participants were females, $63 \%$ were married. A higher proportion $(47 \%)$ of them belonged to the age group of 30-49 years. One-fifth of the participants were students $(20 \%)$, followed by health-care professionals $(20 \%)$, engineers $(10 \%)$, and teachers $(6 \%)$. Rest of the participants were self-employed (9\%) or engaged in other occupation (Table 1).

The overall median (IQR) score of knowledge was 10 (10-11). Although there were differences in median (IQR) between the groups, the study could not establish a statistically significant difference between sociodemographic variables and knowledge scores (Table 2).

In regard to attitude of the participants toward COVID-19, a statistically significant difference was found with gender and marital status with a p-value of 0.03 and 0.047 , respectively (Table 3 ).

Occupational groups, marital status, and age group had significant difference between the groups with at least one of the practices with $\mathrm{p}<0.05$ (Table 4).

\section{DISCUSSION}

The current study demonstrates that a vast majority of participants held an optimistic attitude toward COVID-19 as they believed that it will be controlled. Despite that, the participants were cautious to wear masks while going outside house and avoided going to crowded places. This implies that there is sincere adherence to government's call for social distancing. Almost all respondents had positive perception regarding to community participation in prevention of disease. Knowledge score and region of residence significantly influenced the respondents' protective behavior for COVID-19 and the sample characteristics of the study as majority of respondents are students and health professionals. Increased knowledge can also be attributed to an overwhelming news telecast at this public health emergency. To prevent COVID-19, individual must have adequate knowledge regarding public adherence to control measures taken by government. Inadequate knowledge may lead to high level of stress and fear among respondents akin a study conducted in Qatar [3].

Results of a question pertinent to confidence of winning battle against SARS in our current study were found to be similar to the study conducted
Table 1: Sociodemography of study participants $(n=449)$

\begin{tabular}{lll}
\hline Variable & Frequency (n) & Percentage \\
\hline Age group (in years) & & \\
18-29 & 191 & 42.5 \\
$30-49$ & 211 & 47.0 \\
50 and above & 47 & 10.5 \\
Gender & & \\
Male & 193 & 43.0 \\
Female & 256 & 57.0 \\
Occupation & & \\
Students & 98 & 21.8 \\
Health care professionals & 93 & 20.7 \\
Engineers & 46 & 10.2 \\
Teachers & 25 & 05.6 \\
Self-employed & 42 & 09.4 \\
$\quad$ Others & 145 & 32.3 \\
Marital status & & \\
$\quad$ Married & 283 & 63.0 \\
Unmarried & 166 & 37.0 \\
\hline
\end{tabular}

Table 2: Knowledge regarding COVID-19 among study participants and its association with sociodemography $(n=449)$

\begin{tabular}{llll}
\hline Variable & Median (IQR) & Test value & p-value \\
\hline Age group (in years) & & & \\
$\quad 18-29$ & $10(9-11)$ & 1.46 & 0.48 \\
$30-49$ & $10(10-11)$ & & \\
50 and above & $10(10-11)$ & & \\
Gender** & $10(9-11)$ & -0.229 & 0.82 \\
$\quad$ Male & $10(10-11)$ & & \\
Female & $10(9-11)$ & 5.061 & 0.41 \\
Occupation* & $10(10-11)$ & & \\
$\quad$ Students & $10(10-11)$ & & \\
$\quad$ Health care professionals & & \\
$\quad$ Engineers & $10(10-11)$ & & \\
$\quad$ Teachers & $10(9-11)$ & & \\
$\quad$ Self-employed & $10(9-11)$ & & \\
$\quad$ Others & $10(10-11)$ & 0.091 & \\
Marital status** & $10(9-11)$ & & \\
$\quad$ Married & Unmarried & & \\
\hline * Kruskal-Wallis test **Mann-Whitney U-test &
\end{tabular}

${ }^{*}$ Kruskal-Wallis test, ${ }^{* *}$ Mann-Whitney U-test

in China where 94.7-100\% Chinese residents had confidence that they can win battle against SARS [4-6]. The methodological comparison for such evidence could not be found for Indian settings; however, during SARS epidemic the preparedness was found to be inadequate in a study conducted in a tertiary care hospital in India settings [7]. The optimistic attitude in present case could possibly be due to government's early intervention of complete lockdown in the country.

Attitude toward COVID-19 was found to be optimistic as majority of respondents took precautions to prevent infection by COVID-19: Restricted themselves to move in crowded places and wore masks when going outside. These strict preventive practices could be attributed to the strict prevention and control measures implemented by local governments such as banning public gatherings. Furthermore, it is a result of the residents' good knowledge regarding the infectivity and droplets transmission of the COVID-19 virus. Interestingly, it was found that $24.4 \%$ men had more of risk-taking behavior as they moved outside home more times than females. Similarly, younger age group of 18-29 years did not wear mask while going outside which was found out to be statistically significant. These findings akin the previous studies regarding age and gender patterns of risk-taking behaviors [8-10].

The significant higher risk of not wearing mask and going outside shows the non-seriousness to the situation since most participants belong to higher education status or maybe there were not many cases in the study participant's area. 
Table 3: Attitude regarding COVID-19 among study participants and its association with sociodemography (n=449)

\begin{tabular}{|c|c|c|c|c|c|c|c|}
\hline \multirow[t]{2}{*}{ Variable } & \multicolumn{3}{|c|}{ COVID 19 will finally be successfully controlled } & \multirow[t]{2}{*}{ p-value } & \multicolumn{2}{|c|}{ we can win the battle against COVID 19 virus } & \multirow[t]{2}{*}{ p-value } \\
\hline & Agree (\%) & Disagree (\%) & Unknown (\%) & & Yes $(\%)$ & No (\%) & \\
\hline \multicolumn{8}{|c|}{ Age group (in years) } \\
\hline $18-29$ & $148(77.5)$ & $17(8.9)$ & $26(13.6)$ & \multirow{3}{*}{0.14} & 183 (95.8) & $8(4.2)$ & \multirow{3}{*}{0.32} \\
\hline $30-49$ & $174(82.5)$ & $10(4.7)$ & $27(12.8)$ & & $201(95.3)$ & $10(4.7)$ & \\
\hline 50 and above & $39(83.0)$ & $0(0)$ & $8(17.0)$ & & $47(100)$ & $0(0)$ & \\
\hline \multicolumn{8}{|l|}{ Gender } \\
\hline Male & $156(80.8)$ & $17(8.8)$ & $20(10.4)$ & \multirow[t]{2}{*}{0.03} & $185(95.8)$ & $8(4.2)$ & \multirow[t]{2}{*}{0.89} \\
\hline Female & $205(80.1)$ & $10(3.9)$ & $41(16.0)$ & & $246(96.1)$ & $10(3.9)$ & \\
\hline \multicolumn{8}{|l|}{ Occupation } \\
\hline Students & 75 (76.5) & $9(9.2)$ & $14(14.3)$ & \multirow[t]{6}{*}{0.82} & 95 (96.9) & $3(3.1)$ & \multirow[t]{6}{*}{0.79} \\
\hline $\begin{array}{l}\text { Health-care } \\
\text { professionals }\end{array}$ & $80(86.0)$ & $5(5.4)$ & $8(8.6)$ & & $88(94.6)$ & $5(5.4)$ & \\
\hline Engineers & $37(80.4)$ & $3(6.5)$ & $6(13.1)$ & & $44(95.6)$ & $2(4.4)$ & \\
\hline Teachers & $20(80.0)$ & $1(4.0)$ & $4(16.0)$ & & $24(96.0)$ & $1(4.0)$ & \\
\hline Self-employed & 35 (83.3) & $1(2.4)$ & $6(14.3)$ & & $39(92.9)$ & $3(7.1)$ & \\
\hline Others & $114(78.6)$ & $8(5.5)$ & $23(15.9)$ & & $141(97.2)$ & $4(2.8)$ & \\
\hline \multicolumn{8}{|l|}{ Marital status } \\
\hline Married & $233(82.3)$ & $11(3.9)$ & $39(13.8)$ & \multirow[t]{2}{*}{0.047} & 272 (96.1) & $11(3.9)$ & \multirow[t]{2}{*}{0.86} \\
\hline Unmarried & $128(77.1)$ & $16(9.6)$ & $22(13.3)$ & & 159 (95.8) & $7(4.2)$ & \\
\hline
\end{tabular}

Table 4: Practice regarding COVID-19 among study participants and its association with sociodemography (n=449)

\begin{tabular}{|c|c|c|c|c|c|c|}
\hline \multirow[t]{2}{*}{ Variable } & \multicolumn{2}{|c|}{ Visited crowded place in the past one week } & \multirow[t]{2}{*}{ p-value } & \multicolumn{2}{|c|}{ Worn mask when leaving home in the past one week } & \multirow[t]{2}{*}{ p-value } \\
\hline & Yes $(\%)$ & No (\%) & & Yes $(\%)$ & No (\%) & \\
\hline \multicolumn{7}{|c|}{ Age group (in years) } \\
\hline $18-29$ & $51(26.7)$ & $140(73.3)$ & \multirow[t]{3}{*}{0.225} & $72(37.7)$ & $119(62.3)$ & \multirow[t]{3}{*}{0.005} \\
\hline $30-49$ & $44(20.9)$ & $167(79.1)$ & & $59(28.0)$ & $152(72.0)$ & \\
\hline 50 and above & $8(17.0)$ & $39(83.0)$ & & 7 (14.9) & $40(85.1)$ & \\
\hline \multicolumn{7}{|l|}{ Gender } \\
\hline Male & $47(24.4)$ & $146(74.6)$ & \multirow[t]{2}{*}{0.537} & $56(29.0)$ & $137(71.0)$ & \multirow[t]{2}{*}{0.493} \\
\hline Female & 56 (21.9) & 200 (78.1) & & $82(32.0)$ & $174(68.0)$ & \\
\hline \multicolumn{7}{|l|}{ Occupation } \\
\hline Students & $34(34.7)$ & $64(65.3)$ & \multirow[t]{6}{*}{0.024} & 35 (35.7) & $63(64.3)$ & \multirow[t]{6}{*}{$<0.001$} \\
\hline $\begin{array}{l}\text { Health-care } \\
\text { professionals }\end{array}$ & $24(25.8)$ & $69(74.2)$ & & $39(41.9)$ & $54(58.1)$ & \\
\hline Engineers & $8(17.4)$ & $38(82.6)$ & & $19(41.3)$ & 27 (58.7) & \\
\hline Teachers & $4(16.0)$ & $21(84.0)$ & & $9(36.0)$ & $16(64.0)$ & \\
\hline Self-employed & $9(21.4)$ & $33(78.6)$ & & $11(26.2)$ & 31 (73.8) & \\
\hline Others & $24(16.5)$ & $121(83.5)$ & & $25(17.2)$ & $120(82.8)$ & \\
\hline \multicolumn{7}{|l|}{ Marital status } \\
\hline Married & $51(18.0)$ & $232(82.0)$ & \multirow[t]{2}{*}{0.001} & $74(26.2)$ & 209 (73.8) & \multirow[t]{2}{*}{0.006} \\
\hline Unmarried & $52(31.3)$ & $114(68.7)$ & & $64(38.5)$ & $102(61.5)$ & \\
\hline
\end{tabular}

Such findings suggest that heath education would be the most important effective communication measure to target specific group of population, for example, target intervention of educating adult population or in rural settings with low education status.

This study is the first of its kind that assessed the knowledge, perception, and attitude behavior toward COVID-19 in Indian settings. However, the study has limitations as the sample was purposively selected. Hence, the results cannot be generalized for the whole adult population. Furthermore, the questionnaire asked from the respondent reported behavior rather than observing their actual practice. Henceforth, there might be overestimation of reported practice. There might be a rural urban difference as most of the data were collected from educated urban population and hence that might be confounding to the study's results because rural respondents were less likely to be aware and practicing less protective behavior.

The summary of the study suggests that the overall knowledge among study participants was higher during rapid rise of COVID-19 in India. Good knowledge corresponds to positive attitude and implementing it in day-to-day life. This implies that the government focus on imparting education to general masses through varied means of communication strategies and daily press briefing of status of COVID-19 are encouraging efforts by Indian authorities. Overall, we are optimistic in winning the battle against the coronavirus in near future.

We declare that there are no conflicts of interest. We like to acknowledge technical and scientific support provided by all authors and the participants for sparing their precious time and taking part in the survey.

\section{CONCLUSION}

Since the study provides enhancing effect of knowledge toward protective behaviors, the awareness raising activities and health education through mass media and campaigns, this should urgently be conducted focusing on effectiveness of hand washing, cough etiquette, social distancing, and responsibility to inform suspected cases to local health authority to prevent COVID-19. A nationwide sample is warranted to comprehend the current scenario of knowledge and practices by citizens of India [11].

\section{ACKNOWLEDGMENTS}

I thank and acknowledge the co-authors and study participants for participating in the study. 


\section{AUTHORS CONTRIBUTION}

All the authors contributed to the preparation of final manuscript.

\section{CONFLICT OF INTEREST}

None.

\section{AUTHORS FUNDING}

None.

\section{REFERENCES}

1. Tachfouti N, Slama K, Berraho M, Nejjari C. The impact of knowledge and attitudes on adherence to tuberculosis treatment: A case-control study in a Moroccan region. Pan Afr Med J 2012;12:1-8.

2. Ajilore K, Atakiti I, Onyenankeya K. College students' knowledge, attitudes and adherence to public service announcements on Ebola in Nigeria: Suggestions for improving future Ebola prevention education programmes. Health Educ J 2017;76:648-60.

3. Bener A, Al-Khal A. Knowledge, attitude and practice towards SARS.
J R Soc Promot Health 2004;124:167-70.

4. Chen S, Qiu Z, Xu L, Chen J, Lin Y. People groups' responses to SARS in the community. Chin Rural Health Serv Adm 2003;23:15-8.

5. Zhou X, Xiu C, Chu Q. Prevention and treatment knowledge and attitudes towards SARS of urban residents in Qingdao. Prev Med Trib 2004;10:407-8.

6. Liu Z, Gao H, Zhang S. Prevention and treatment knowledge towards SARS of urban population in Jinan. Prev Med Trib 2004;10:659-60.

7. Goel S, Gupta AK, Singh A, Lenka SR. Preparations and limitations for prevention of severe acute respiratory syndrome in a tertiary care centre of India. J Hosp Infect 2007;66:142-7.

8. Pawlowski B, Atwal R, Dunbar RIM. Sex differences in everyday risktaking behavior in humans. Evol Psychol 2008;6:29-42.

9. Cobey KD, Stulp G, Laan F, Buunk AP, Pollet TV. Sex differences in risk taking behavior among Dutch cyclists. Evol Psychol 2013;11:350-64.

10. Duell N, Steinberg L, Icenogle G, Chein J, Chaudhary N, Di Giunta L, et al. Age patterns in risk taking across the world. J Youth Adolesc 2018;47:1052-72.

11. Neela B, Jakkula S, Mujeebuddin, Gaur RP. Corticosteroids and secondary infections: An insight into coronavirus disease-2019. Asian J Pharm Clin Res 2021;14:36-47. 